\title{
Promoting Involvement of the People Living with HIVIAIDS (PLWHA) Participate in Social/Community in Cambodia
} Keo Chen and Meas Ramo*

\author{
Address: Cambodian People living with HIV/AIDS Network (CPN) \\ Email: Meas Ramo* - cpn@online.com.kh \\ * Corresponding author $\ddagger$ Presenting author
}

from 2005 International Meeting of The Institute of Human Virology

Baltimore, USA, 29 August - 2 September 2005

Published: 8 December 2005

Retrovirology 2005, 2(Suppl I):P83 doi:I0.I 186/1742-4690-2-SI-P83

\section{Issues}

Cambodia has rapidly growing HIV/AIDS epidemic, one of the worst in Southeast Asia.

\section{Project}

Partnership between public health, medical institution, PLWHA groups and NGOs at operational district level, and strong referral system between the home, community and institutional care providers are necessary for development of a successful comprehensive HIV/AIDS care and support, especially those that were coverage PLWHA in Cambodia. By underpinning systematic involvement of PLWHA at national, provincial, operational district and community level, the project aims to support PLWHA groups going through their self empowerment process from dependent phase in which NGOs/hospital arrange activities and they are recipients of the services, to partnership phase in which PLWHA facilitate active participation in services delivery in Cambodia.

\section{Results}

Cambodian People Living with HIV/AIDS Network $(\mathrm{CPN}+)$ to assist the Ministry of Health and National AIDS Authority. The sector will be working specially to assist developing care, treatment and other support services, and to facilitate referral systems among available services.

\section{Lesson Learned}

Reinforcement of PLWHA groups and policy making bodies resulted in a successful operational of the $\mathrm{CPN}+$ strategic. 